\title{
Focus on Harsh Environment and Field-Portable Mass Spectrometry: Editorial
}

$\mathrm{R}$ ecently there has been considerable interest and excitement over the long-awaited rendezvous of the Rosetta Mission, launched in 2004, with the Comet 67P/ChuryumovGerasimenko. This event is an incredible testament to the success of science and technology for exploring the physical world beyond our own planet. Arguably, this mission involves one of the harshest environments that our technology is facing. On this mission is ROSINA, the Rosetta Spectrometer for Ion and Neutral Analysis, which consists of two mass spectrometers, a double focusing magnetic sector, and a reflectron timeof-flight. The presence of these instruments on this mission reflects the significant impact and insight that mass spectrometers provide about our environment, as well the trust we place in that data. It is the reliability of data and the amazingly diverse and powerful capabilities that cause us to seek applications for mass spectrometry outside of the laboratory.

It can be argued that a true "harsh environment" for a mass spectrometer is simply taking the instrument outside the confines of the well-controlled setting of the laboratory. Bench-top mass spectrometers are not small; they require vacuum, sensitive detectors, ion sources, and much power to operate all these components. It is in this arena where the Harsh Environment Mass Spectrometry Workshop and community have had the greatest impact. The research innovations among this group of investigators have taken mass spectrometry to the battlefield, underwater, on Mars, in volcanoes, and into the gas fields. This wide applicability cannot be accomplished without solving some fundamental issues involving component modifications for ruggedness and portability.

As we have seen from the influx of small focused mass spectrometry instrumentation, there is a significant demand in the marketplace for low cost, low size/mass, and field deployable chemical analyzers. For law enforcement, there is a greater need to analyze samples at the crime scene or detect contraband remotely. For defense agencies, there is an increasing demand to analyze the immediate airspace around and ahead of the advance of troops. For security applications, weapons and explosive devices must also be detected in wide-ranging locations, including the public domain (e.g., airports, transportation systems). The medical community requires low mass, low volume, and low cost analyzers for diagnosis of disease. In addition, for specific environmental concerns and increased development of sustainable energy resources, mass

Correspondence to: Veronica Bierbaum; e-mail: veronica.bierbaum (a)Colorado.EDU spectrometry is becoming the main tool for providing field data. Every day, these devices are required to reduce false positives, increase reliability, improve selectivity, and enhance sensitivity. As knowledge of the chemical environment is growing at a rapid pace, there is also a requirement that detectors be adaptable and able to address these new interests. The only detection technology that can meet these requirements rapidly is a mass spectrometer.

The Harsh Environment Mass Spectrometry (HEMS) Workshop was created as an ASMS Workshop in 1999 as a means of encouraging interaction among people involved in deploying mass spectrometers outside of the typical laboratory setting. This does not always mean small and field-portable, but requires an instrument that yields good data in an often nonideal setting for the mass spectrometer. The HEMS group has met on both the East and West coasts and hosts the Workshop every odd year in the early Fall. The papers presented in this HEMS Special Focus represent just a modest sampling of the technological developments discussed and disseminated within this group. These accomplishments have had the impact of not only solving the problems of field analysis but also of advancing mass spectrometry technology for lab instrumentation and sampling as well.

This Journal of the American Society for Mass Spectrometry (JASMS) Special Focus on Harsh Environment and FieldPortable Mass Spectrometry brings together a collection of 11 research papers that represent the richness and broad achievements in the field:

(1) "The Effect of the Earth's and Stray Magnetic Fields on Mobile Mass Spectrometer Systems" by Ryan J. Bell, Nicholas G. Davey, Morten Martinsen, R. Timothy Short, Chris G. Gill, and Erik T. Krogh.

(2) "A Field-Portable Membrane Introduction Mass Spectrometer for Real-Time Quantitation and Spatial Mapping of Atmospheric and Aqueous Contaminants" by Ryan J. Bell, Nicholas G. Davey, Morten Martinsen, Christian CollinHansen, Erik T. Krogh, and Christopher G. Gill.

(3) "Mass Spectrometry in the Home and Garden" by Christopher J. Pulliam, Ryan M. Bain, Joshua S. Wiley, Zheng Ouyang, and R. Graham Cooks.

(4) "Membrane Inlet Mass Spectrometry for Homeland Security and Forensic Applications" by Stamatios Giannoukos, Boris Brkić, Stephen Taylor, and Neil France.

(5) "Design of Portable Mass Spectrometers with Handheld Probes: Aspects of the Sampling and Miniature Pumping Systems" by Chien-Hsun Chen, Tsung-Chi Chen, Xiaoyu 
Zhou, Robert Kline-Schoder, Paul Sorensen, R. Graham Cooks, and Zheng Ouyang.

(6) "Two-Dimensional Aperture Coding for Magnetic Sector Mass Spectrometry" by Zachary E. Russell, Evan X. Chen, Jason J. Amsden, Scott D. Wolter, Ryan M. Danell, Charles B. Parker, Brian R. Stoner, Michael E. Gehm, David J. Brady, and Jeffrey T. Glass.

(7) "Airborne Single Particle Mass Spectrometers (SPLAT II $\&$ miniSPLAT) and New Software for Data Visualization and Analysis in a Geo-Spatial Context" by Alla Zelenyuk, Dan Imre, Jacqueline Wilson, Zhiyuan Zhang, Jun Wang, and Klaus Mueller.

(8) "Analysis of Polycyclic Aromatic Hydrocarbons using Desorption Atmospheric Pressure Chemical Ionization Coupled to a Portable Mass Spectrometer" by Fred P. M. Jjunju, Simon Maher, Anyin Li, Abraham K. BaduTawiah, Stephen Taylor, and R. Graham Cooks.

(9) "Development of Multi-Membrane Near-Infrared Diode Mass Spectrometer for Field Analysis of Aromatic Hydrocarbons" by Phillip M. Mach, Kenneth C. Wright, and Guido F. Verbeck.

(10) "Performance Evaluation of a Loeb-Eiber Mass Filter at 1 Torr" by William D. Hoffmann, Feng Jin, Randall E. Pedder, Christopher Taormina, and Glen P. Jackson.

(11) "Unmanned Aerial Mass Spectrometer Systems (UASMS) for In-Situ Volcanic Plume Analysis" by Jorge Andres Diaz, David Pieri, Kenneth Wright, Paul Sorensen, Robert Kline-Shoder, C Richard Arkin, Matthew Fladeland, Geoff Bland, Maria Fabrizia Buongiorno, Carlos Ramirez, Ernesto Corrales, Alfredo Alan, Oscar Alegria, David Diaz, and Justin Linick.
These papers describe major advances in component design and significant refinements in instrument operation, and utilize a host of mass filtering techniques (e.g., ion trap, time-of-flight, quadrupole, triple-quadrupole, and Loeb-Eiber). These developments make available an arsenal of devices with increased portability, sensitivity, and versatility. The applications of these instruments are amazingly diverse - from the relatively benign setting of "home and garden" to the hazardous environment of volcanic emissions.

JASMS is pleased to present this Special Focus on Harsh Environment and Field-Portable Mass Spectrometry. We look forward to an equally exciting future of development and research.

\section{Guido F. Verbeck}

President, HEMS Society and Guest Editor, JASMS

Department of Chemistry

University of North Texas

Denton, Texas, USA

Veronica M. Bierbaum

Associate Editor, JASMS

Department of Chemistry and Biochemistry

University of Colorado

Boulder, Colorado, USA

e-mail:veronica.bierbaum@Colorado.EDU 